\title{
Interventional Pain Medicine Practice in the UK and the USA: A Survey of 242 Pain Physicians
}

\author{
Sanjeeva Gupta, MD ${ }^{1}$ and Manohar Sharma, MD²
}

From: ${ }^{1}$ Department of Anaesthesia, Pain Medicine and Intensive Care, Bradford Teaching Hospitals NHS Foundation Trust, Bradford Royal Infirmary, Bradford, West Yorkshire, UK; ${ }^{2}$ The Walton Centre NHS Foundation Trust, Liverpool, UK

Address Correspondence: Sanjeeva Gupta, MD Consultant in Pain Medicine and Anaesthesia, Department of Anaesthesia, Pain Medicine and Intensive Care, Bradford Teaching Hospitals NHS Foundation Trust, Bradford Royal Infirmary, Duckworth Lane Bradford, West Yorkshire BD9 6RJ, UK

E-mail: stoppain@btinternet. com

Disclaimer: There was no external funding in the preparation of this manuscript. Conflict of interest: Each author certifies that he or she, or a member of his or her immediate family, has no commercial association (i.e., consultancies, stock ownership, equity interest, patent/licensing arrangements, etc.) that might pose a conflict of interest in connection with the submitted manuscript.

Manuscript received: 07-16-2019 Revised manuscript received: 09-23-2019

Accepted for publication: 10-03-2019

Free full manuscript: www.painphysicianjournal.com
Background: Pain medicine practices vary across different regions within a country and between countries.

Objectives: The objective of the survey was to study the variation in interventional pain medicine practices in the United Kingdom (UK) and the United States (US).

Methods: A survey was designed in 2019 on Survey Monkey ${ }^{\circledR}$. Pain physicians from the UK and the US were invited to respond.

Results: A total of 120 responses were received from pain physicians in the UK and 122 from the US. Twenty-six percent and $90 \%$ of pain physicians in the UK and US, respectively, are in full-time pain medicine practice. There was marked variation in the utilization of diagnostic medial branch blocks before performing radiofrequency denervation (RFD) between the UK and the US. In the UK, $42 \%$ of pain physicians, and $50 \%$ in the US, use a 20 -gauge or a 22 -gauge radiofrequency needle for lumbar RFD. Around $30 \%$ to $50 \%$ of pain physicians, both in the UK and the US, discontinued antithrombotic agents before medial branch blocks at all the spinal levels. Around $50 \%$ of pain physicians in the UK and US are stopping anticoagulants before lumbar and cervical RFD. Over $95 \%$ of UK and US respondents stopped antithrombotic agents for interlaminar and transforaminal epidural injections along the spine. At the lumbar level, $51 \%$ of pain physicians in the UK and $47 \%$ in the US use a particulate steroid for the initial lumbar transforaminal epidural injection (TFESI); and $4 \%$ and $14 \%$ in the UK and US, respectively, use a particulate steroid for initial cervical TFESI. Eight percent of pain physicians in the UK and 20\% from the US would switch to a particulate steroid if the initial TFESI with a nonparticulate steroid did not provide satisfactory pain relief. Ten percent of pain physicians from the United Kingdom and $20 \%$ from the US believed that this switch provides better pain relief.

Limitations: Interventional pain physicians from the UK and the US were invited to respond. This may not reflect global practice.

Conclusions: Our survey has highlighted the wide variation in interventional pain medicine practices both in the UK and the US. The relevant governing bodies in the UK and in the US should encourage clinicians to use at least an 18-gauge radiofrequency needle for RFD at the lumbar level. Discontinuing antithrombotic agents for the lumbar medial branch block is not justifiable. Pain physicians must discuss the advantages and disadvantages of using a nonparticulate over a particulate steroid preparation with the patient before performing TFESI as a standard procedure during the consenting process.

Key words: Antithrombotic agents, epidural steroid, medial branch blocks, pain practice variations, particulate and nonparticulate steroids, radiofrequency denervation, spinal interventions

Pain Physician 2020: 23:127-134 
P ain medicine practice varies in different regions both within and between countries. The selection criteria and techniques used for radiofrequency denervation (RFD) of medial branches for spinal pain vary considerably among pain physicians (1). Patients needing spinal interventions can be on anticoagulants and antiplatelet agents (antithrombotic agents) for various comorbidities. There is increasing evidence that stopping antithrombotic agents for some spinal interventions may be riskier than continuing them. The American Society of Interventional Pain Physicians (ASIPP) has published "Responsible, Safe, and Effective Use of Antithrombotics and Anticoagulants in Patients undergoing Interventional Techniques" in 2019 (2).

There has been a lot of debate in the literature regarding the use of particulate or nonparticulate steroids for TFESI. The British Pain Society and the Faculty of Pain Medicine have published a consensus statement on this topic (3-6). This survey was designed to assess current interventional pain practices in the United Kingdom (UK) and the United States (US).

\section{Methods}

A survey was designed in 2019 on Survey Monkey ${ }^{\oplus}$. Pain physicians from the UK and the US were invited to respond.

See Table 1 for the questions asked within the survey.

\section{Results}

A total of 120 responses were received from pain physicians in the UK and 122 from the US.

Twenty-six percent and $90 \%$ of pain physicians in the UK and US, respectively, are in full-time pain medicine practice. In the UK, $17 \%$ of pain physicians performed more than 50 pain interventions per month, compared to $81 \%$ from the US.

In the UK, $44 \%$ of pain physicians performed one diagnostic lumbar medial branch block (MBB) and 32\% performed generally one but sometimes 2 MBBs before lumbar RFD, compared to $9 \%$ and $21 \%$, respectively, by US pain physicians. In the US, $59 \%$ of pain physicians always performed 2 sets of MBBs before RFD.

Figures 1 and 2 show the radiofrequency needle gauges (G) used at different levels of the spine by pain physicians in the UK and the US.

Tables 2 and 3 show the percentage of pain physicians in the UK and the US either stopping or continuing anticoagulants for MBBs, RFD, interlaminar epidural injections, and transforaminal epidurals along the spine.

Over $95 \%$ of the respondents from the UK and the US stop antithrombotic agents for interlaminar and TFESI along the spine.

Figures 3 to 5 show the percentage of pain physicians in the UK and the US using particulate and nonparticulate steroids for the first/initial lumbar, cervical, and thoracic TFESI.

Figure 6 shows the percentage of pain physicians switching to a particulate steroid if the first TFESI with

Table 1. Questions asked in survey of pain physicians in the United Kingdom and the United States.

\begin{tabular}{|l|l|}
\hline 1. Proportion of time devoted to pain medicine practice. \\
\hline 2. On average how may pain injections/interventions do you perform per month? \\
\hline 3. Please indicate the areas of spine at which you perform radiofrequency denervation (RF) in your practice (can include more than one area). \\
\hline 4. On average how many radiofrequency denervation (RFD) procedures do you perform every month? \\
\hline 5. Before listing the patient from lumbar radiofrequency denervation, how many times do you perform diagnostic medial branch blocks? \\
\hline 6. How many times do you perform diagnostic sacroiliac joint block/lateral branch block before sacroiliac joint radiofrequency denervation? \\
\hline 7. Please indicate the needle you use for lumbar, thoracic, and cervical radiofrequency denervation (RFD) procedure. \\
\hline $\begin{array}{l}\text { 8. Do you stop anticoagulants/antiplatelet agents (excluding } 75 \text { mg aspirin) before performing diagnostic medial branch blocks (MBB) } \\
\text { along the spine, sacroiliac joint injection (SIJ), radiofrequency denervation (RFD) along the spine, interlaminar epidural along the spine, } \\
\text { transforaminal epidural injection (TFESI) along the spine, and caudal epidural? }\end{array}$ \\
\hline $\begin{array}{l}\text { 9. Which steroid preparation do you use when you perform the first/initial transforaminal epidural (TFESI)/nerve root block at the lumbar, } \\
\text { thoracic, and cervical level? }\end{array}$ \\
\hline $\begin{array}{l}\text { 10. If the initial/first transforaminal epidural injection/nerve root block with dexamethasone (nonparticulate) does not provide adequate pain } \\
\text { relief for a satisfactory duration, do you then use a particulate steroid (depo-medrone; triamcinolone, etc.)? }\end{array}$ \\
\hline $\begin{array}{l}\text { 11. In your experience when you change from a nonparticulate (dexamethasone) steroid for the first TFESI to a particulate steroid (depo- } \\
\text { medrone, triamcinalone) for the second TFESI in the same patient, does this generally provide a better and longer duration of pain relief? }\end{array}$ \\
\hline
\end{tabular}


Fig. 1. Percentage of respondents in the United Kingdom and the United States using 16-, 18-, 20 -, and 22-gauge radiofrequency needles for lumbar medial branch radiofrequency denervation.

60

40

20

10
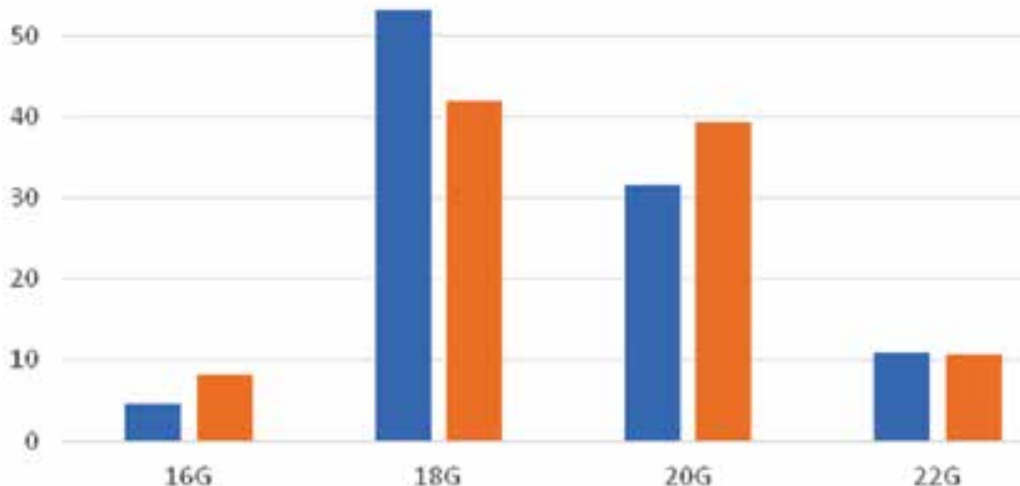

Abbreviations: G, gauge

$16 G$

$18 G$

UK EUSA

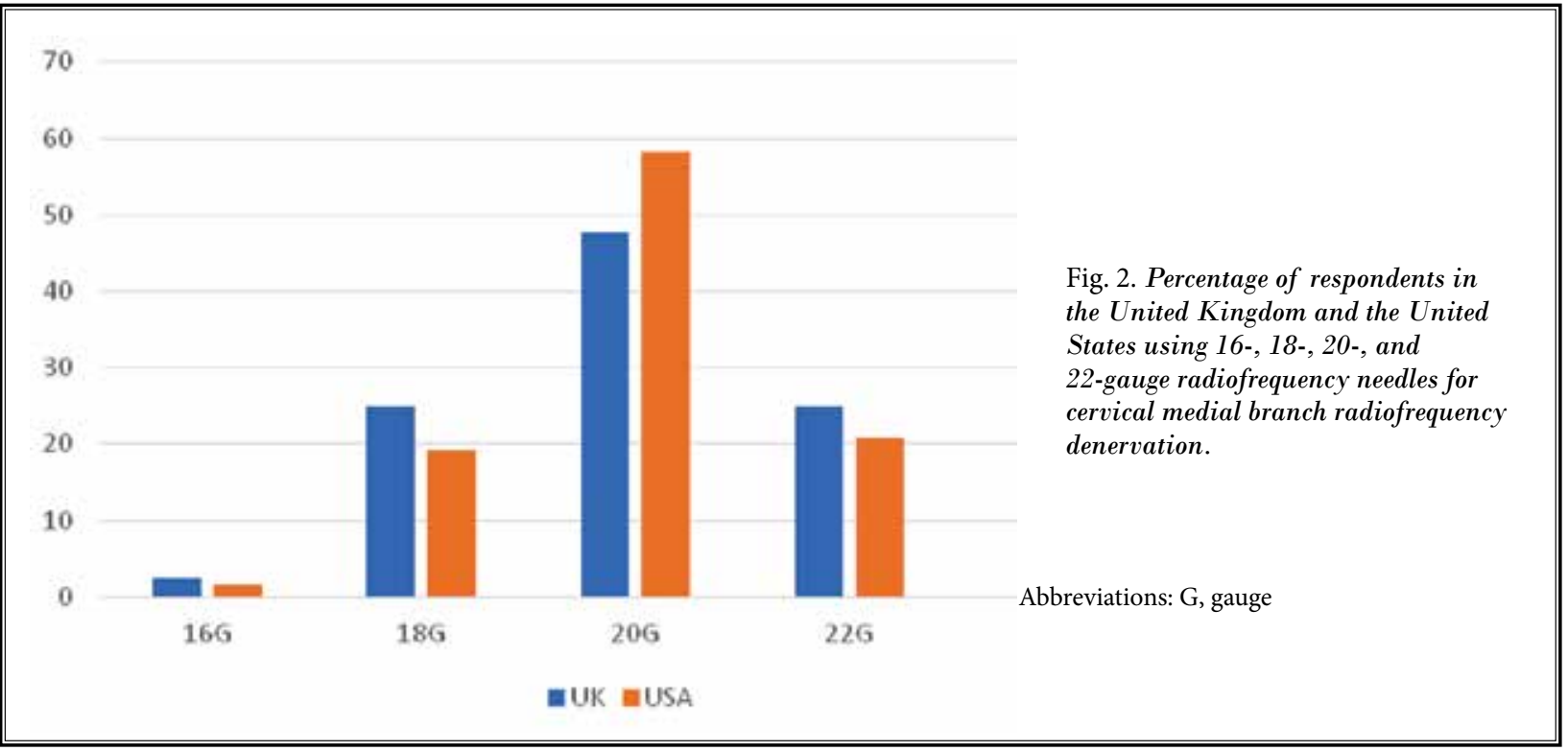

Table 2. Table showing the percentage of pain physicians either stopping or continuing anticoagulants for medial branch block or sacroiliac joint block in the United Kingdom and the United States.

Abbreviations: MBB, medial branch block; SIJ, sacroiliac joint

\begin{tabular}{|l|c|c|c|c|c|c|}
\hline $\begin{array}{c}\text { Do you stop anticoagulants/ } \\
\text { antiplatelet agents before }\end{array}$ & \multicolumn{2}{|c|}{ YES } & \multicolumn{2}{c|}{ No } & \multicolumn{2}{c|}{$\begin{array}{c}\text { I don't do this } \\
\text { Procedure }\end{array}$} \\
\hline & UK & USA & UK & USA & UK & USA \\
\hline Lumbar MBB & $36 \%$ & $28 \%$ & $60 \%$ & $72 \%$ & $4 \%$ & $0 \%$ \\
\hline Cervical MBB & $55 \%$ & $45 \%$ & $26 \%$ & $54 \%$ & $19 \%$ & $1 \%$ \\
\hline Thoracic MBB & $30 \%$ & $31 \%$ & $37 \%$ & $60 \%$ & $33 \%$ & $9 \%$ \\
\hline SIJ Block & $30 \%$ & $15 \%$ & $62 \%$ & $79 \%$ & $8 \%$ & $6 \%$ \\
\hline
\end{tabular}




\begin{tabular}{|l|c|c|c|c|c|c||}
\hline $\begin{array}{c}\text { Do you stop anticoagulants/ } \\
\text { antiplatelet agents before }\end{array}$ & \multicolumn{2}{|c|}{ YES } & \multicolumn{2}{c|}{ No } & \multicolumn{2}{c|}{$\begin{array}{c}\text { I don't do this } \\
\text { procedure }\end{array}$} \\
\hline & UK & USA & UK & USA & UK & USA \\
\hline Lumbar MBB RFD & $58 \%$ & $49 \%$ & $35 \%$ & $51 \%$ & $7 \%$ & $0 \%$ \\
\hline Cervical MBB RFD & $59 \%$ & $58 \%$ & $17 \%$ & $40 \%$ & $24 \%$ & $2 \%$ \\
\hline Thoracic MBB RFD & $32 \%$ & $44 \%$ & $20 \%$ & $44 \%$ & $48 \%$ & $12 \%$ \\
\hline SIJ RFD & $43 \%$ & $35 \%$ & $31 \%$ & $46 \%$ & $26 \%$ & $19 \%$ \\
\hline
\end{tabular}

Table 3. Table showing the percentage of pain physicians either stopping or continuing anticoagulants for medial branch radiofrequency denervation or sacroiliac joint radiofrequency denervation in the United Kingdom and the United States.

Abbreviations: MBB, medial branch block; RFD, radiofrequency denervation; SIJ, sacroiliac joint
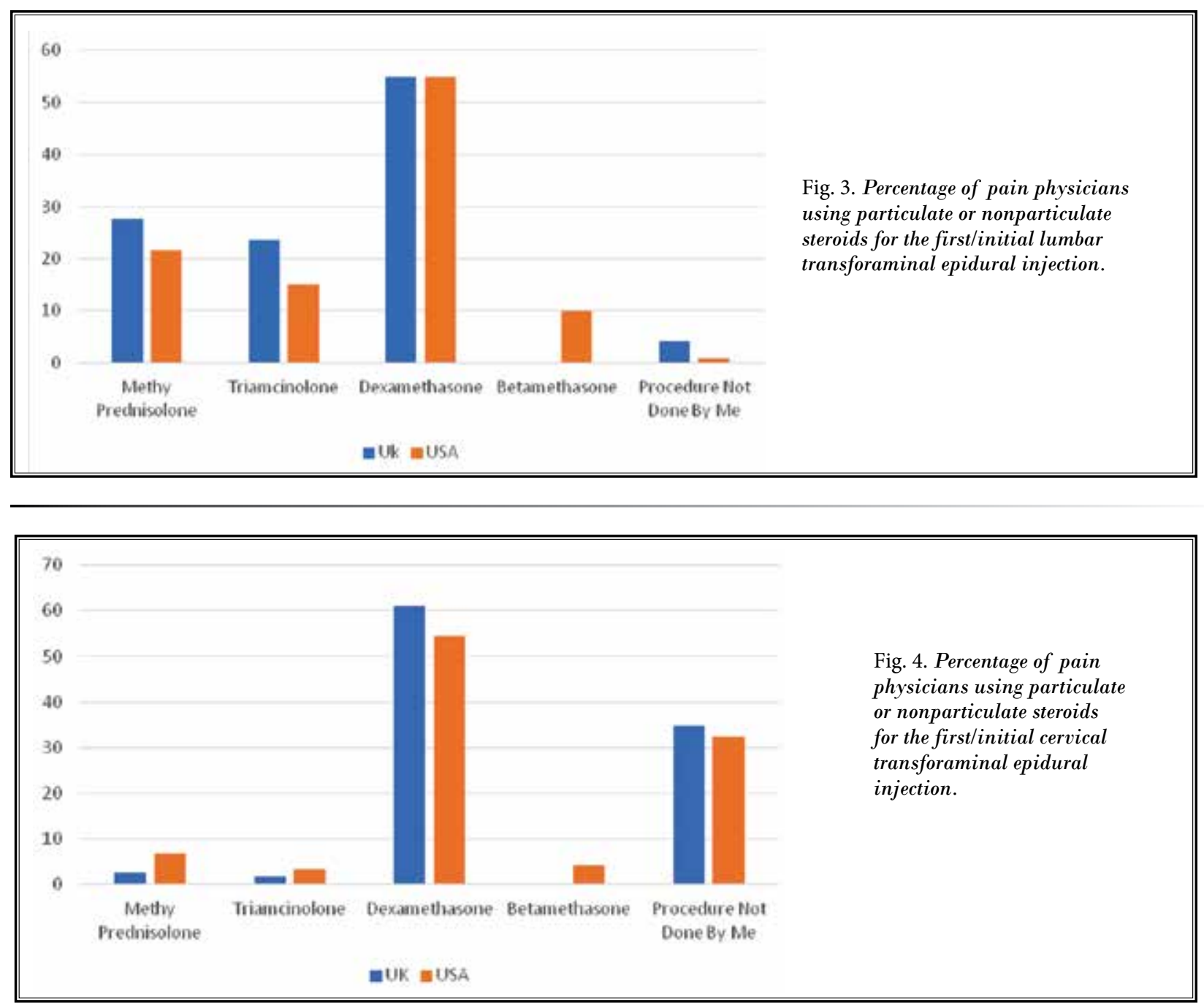

dexamethasone does not provide satisfactory pain relief.

Figure 7 shows the percentage of pain physicians who believe that changing from dexamethasone (nonparticulate) to a particulate steroid for the second TFESI provides better pain relief.

\section{Discussion}

Most pain physicians in the US practice full-time pain medicine and this is reflected in the higher number of interventions performed compared to UK pain physicians. The UK National Institute for Health and Care Excellence (NICE) low back pain clinical guidelines 

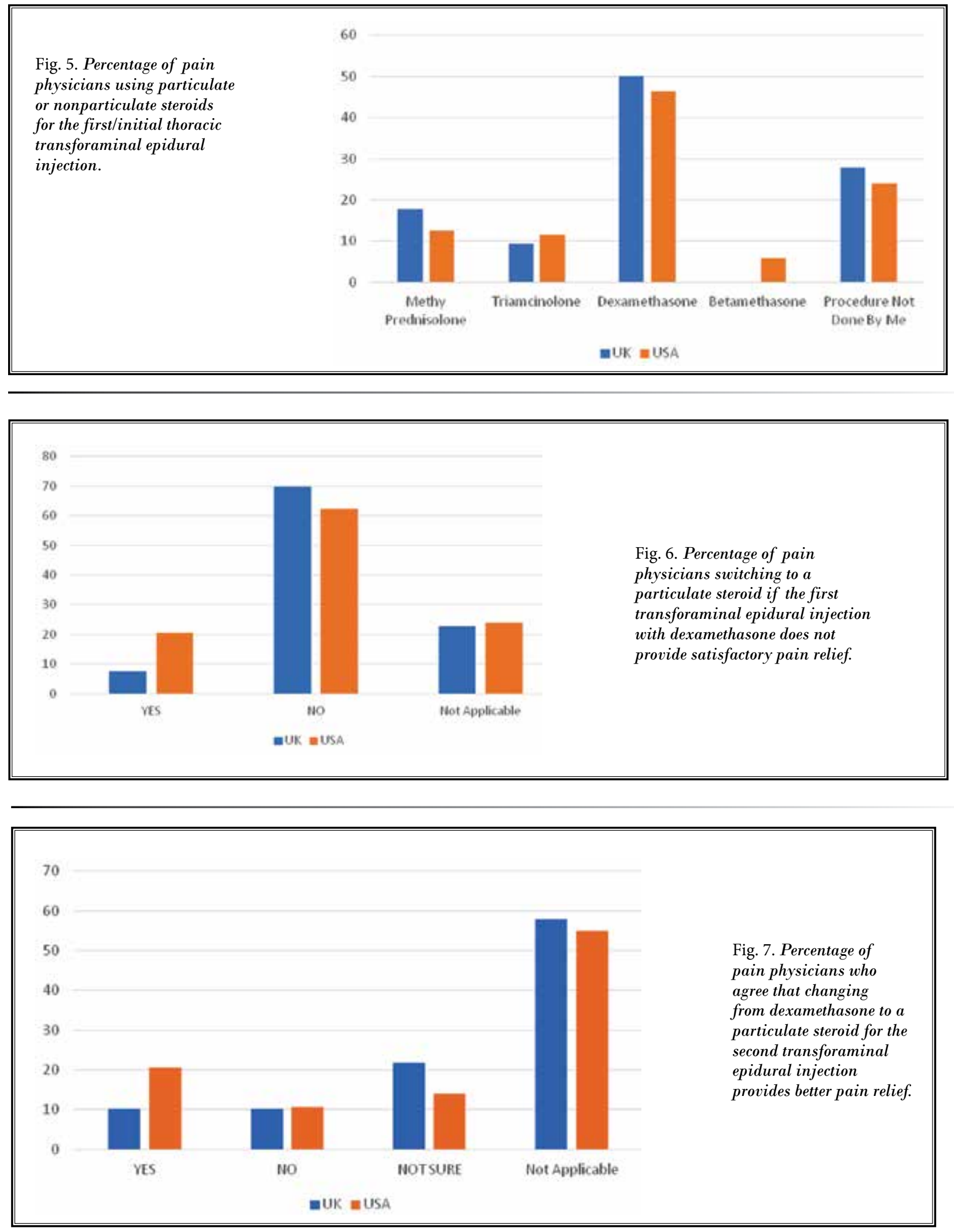
(CG 59) recommend one set of lumbar MBBs before lumbar RFD (7). A significant number of pain physicians in the UK perform one set of diagnostic lumbar MBBs before RFD. However, $59 \%$ of pain physicians in the US perform diagnostic MBBs twice before RFD, as recommended by some of the pain organizations/societies (8). The same pattern is observed for diagnostic sacroiliac joint block (SIJ) preceding RFD in the UK and the US. Some studies have shown that the outcome of the lumbar RFD procedure is better when 2 sets of diagnostic MBBs are performed before the RFD (1,8-10). However, when considering the cost-effectiveness of RFD procedures for facet joint-mediated pain, there are wideranging views and recommendations (11). It is possible that differences in practice between the UK and the US are due to the significant differences in the health care systems across these countries.

It was surprising to find that $42 \%$ of pain physicians in the UK and $50 \%$ in the US use a $20-\mathrm{G}$ or a $22-\mathrm{G}$ RFD needle for lumbar RFD. For cervical RFD procedures, this figure, i.e., the use of smaller-diameter or higher-G RF needles is $73 \%$ in the UK and $79 \%$ in the US; however, for thoracic RFD procedures, the usage is $49 \%$ in the UK and $71 \%$ in the US. We did not explore why some pain physicians were not using lower-G RF needles. However, we suspect that this could be due to inadequate training, fear of discomfort to the patient, and perceived complications that may be associated with smaller-G RF needles. We are aware that if one is using a smallerdiameter needle (higher-G), the lesion size may be increased by using multiple lesions (as many as 6 lesions for a 22-G RF needle) at the target site. We, however, did not ask how many lesions were done by those using a higher G. Although there is no published evidence to indicate that the outcome of RFD is better with a smaller-G RF needle, it is accepted clinical practice in most pain units that the smaller-G RF needles produce larger lesions; this increases the chances of lesioning the target medial branch, increasing the probability of better outcomes (1). Performing multiple lesions at each level increases the duration of the procedures, adding to the theatre utilization cost.

A significant number of pain physicians, both in the UK and the US, are discontinuing the antithrombotic agents before MBBs at all spinal levels. Stopping these agents poses the serious and fatal risk of thromboembolic events, but continuation can cause bleeding and its associated complications. Endreas et al (12) had "zero" complications following lumbar MBBs in 1836 patients and following SIJ in 261 patients in whom anticoagulants were continued. The lumbar MBB procedure is a paraspinal injection and the risk of bleeding leading to epidural haematoma is very low. Therefore, it is difficult to justify stopping antithrombotic agents for such procedures. The ASIPP (2) and American Society of Regional Anesthesia and Pain Medicine (ASRA) (13) guidelines on safe and effective use of antithrombotic and anticoagulants classify the interventional procedures as low, intermediate, and high-risk and suggest that other existing comorbidities should be considered before deciding if these agents could be discontinued. The probability of bleeding and its complications may be less if thinner needles (e.g., 25-G) are used. However, the Spinal Intervention Society (SIS) practice guidelines (14) recommends that there is no need to stop the use of anticoagulants for MBBs and intraarticular injections along the spine, as they are extraspinal procedures. The SIS guidelines require that patients are diligently monitored for possible development of paraspinal or epidural haematoma and the procedures are performed as described in these guidelines.

Best practice would be to individualize the decision to stop or continue antithrombotic agents depending on the reasons for which they were started, the planned procedure, the $\mathrm{G}$ of needle used for the procedure, and associated comorbidities. The risks of both stopping and continuing antithrombotic agents should be explained to the patient and, if necessary, an opinion from the physician who started the antithrombotic agent should be obtained and a shared decision taken. This should also prompt an informed discussion as to whether the intended procedure is truly necessary or warranted in the context of overall risks and benefits and in view of the natural history of the pain being treated.

TFESI with a nonparticulate steroid has been shown to be noninferior to a particulate steroid preparation $(15,16)$. However, in our survey we found that at the lumbar level, $51 \%$ of pain physicians in the UK and $47 \%$ in the US use a particulate steroid for the initial lumbar TFESI; $4 \%$ of UK physicians and $14 \%$ of US physicians use particulate steroid for initial cervical TFESI, and $27 \%$ of UK physicians and $30 \%$ of US physicians use particulate steroid for initial thoracic TFESI. Eight percent of pain physicians in the UK and $20 \%$ from US would switch to a particulate steroid if the initial TFESI with a nonparticulate steroid did not provide satisfactory pain relief. Ten percent of UK pain physicians and $20 \%$ of US pain physicians believed that this switch provides better pain relief. In our opinion, the number of pain physicians in the UK and the US switching from a nonparticulate to a 
particulate steroid for the second TFESI may have been higher had we specified in our survey that these 2 questions were for lumbar TFESI only.

This survey has highlighted that, despite recommendations to use a nonparticulate steroid for the initial TFESI, a significant proportion of pain physicians in the UK and the US have continued to use a particulate steroid. It is encouraging to know that most pain physicians in the UK and the US used a nonparticulate steroid for cervical TFESI. However, there has also been a report of conus injury reported after using dexamethasone for lumbar TFESI (17). Pain physicians must discuss and document the pros and cons of using nonparticulate or particulate steroids with the patient before performing TFESI as standard practice during the consenting process for the procedure.

Although there are multiple guidelines published on the subject matter covered by our survey, it appears that these are not being followed by a good number of UK and US pain physicians. Following an online survey of UK pain physicians regarding the awareness and usefulness of the guidelines published by the Faculty of Pain Medicine and the British Pain Society, it has become clear that the awareness of various guidelines varied significantly (between $38 \%$ and $90 \%$ ). We note that the surveys motivated $89 \%$ of the respondents to look at the guidelines (18). Common barriers to implementation include professionals perceiving that they have insufficient time to learn, adopt, or implement a new intervention, or believing that it would add to their existing workload (19). It will be very helpful if organizations preparing guidelines could also publish guidance on development, dissemination, and implementation strategies when they are published. We are in the process of developing a guiding document to bridge the gap between knowledge and clinical practice (20).

\section{Conclusions}

Our survey has highlighted wide variation in interventional pain medicine practices both in the UK and the US. The relevant governing bodies in the UK and the US should encourage clinicians to use at least an 18-G RF needle for RFD at lumbar levels followed by the same at cervical and thoracic levels. Adequate training opportunities should be provided so that pain physicians can gain confidence in using larger-size (smallerG) RF needles.

The decision to stop or continue antithrombotic agents must be individualized depending on the reasons for which they were started, the nature of the planned procedure, the $\mathrm{G}$ of needle used for the procedure, and associated comorbidities. Stopping antithrombotic agents for lumbar MBBs may not be justifiable. Pain physicians must discuss the advantages and disadvantages of using either nonparticulate or particulate steroids with the patient before performing TFESI as part of the consenting process for the procedure.

\section{References}

1. Dreyfuss P, Halbrook B, Pauza K, Joshi A, McLarty J, Bogduk N. Efficacy and validity of radiofrequency neurotomy for chronic lumbar zygapophysial joint pain. Spine 2000; 25:1270-1277.

2. Kaye AD, Manchikanti L, Novitch $M B$, et al. Responsible, safe, and effective use of antithrombotics and anticoagulants in patients undergoing interventional techniques: American Society of Interventional Pain Physicians (ASIPP) Guidelines. Pain Physician 2019; 22:S75-S128.

3. Collighan N, Gupta S, Richardson J. Comparison of the effectiveness of lumbar transforaminal epidural injection with the particulate and nonparticulate corticosteroids in lumbar radiating pain. Pain Med 2011; 12:1290-1291.
4. Makkar JK, Singh PM, Jain D, Goudra B. Particulate vs non-particulate steroids for transforaminal epidural steroid injections: Systematic review and metaanalysis of the current literature. Pain Physician 2016; 19:327-340.

5. Lee J, Gupta S, Price C, Baranowski AP. Low back and radicular pain: A pathway for care developed by the British Pain Society. Br J Anaesth 2013; 111:112-120.

6. British Pain Society/Faculty of Pain Medicine (RCA) Consensus Statement on the use of Corticosteroids for Neuraxial Procedures in the UK. The British Pain Society Web site. Date Published 11/01/2018. Date Accessed 06/03/2019. https://www.britishpainsociety.org/ static/uploads/resources/files/BPS_ FPM_Steroid_Statement_FINAL.pdf
7. Low back pain and sciatica in over 16s: Assessment and management. NICE guideline (NG59). National Institute for Health and Care Excellence Web site. Date Published 11/2016. Date Accessed 05/03/2019. www.nice.org.uk/guidance/ ng59

8. Bogduk N. Lumbar medial branch blocks. In: Bogduk N (ed). Practice Guidelines for Spinal Diagnostic and Treatment Procedures. 2nd ed. San Francisco, International Spinal Intervention Society, 2013: pp. 559-599.

9. Derby R, Melnik I, Lee J, Lee S. Correlation of lumbar medial branch neurotomy results with diagnostic medial branch block cutoff values to optimize therapeutic outcome. Pain Med 2012; 13:1533-1546. 
10. Nath S, Nath CA, Pettersson K. Percutaneous lumbar zygapophysial (facet) joint neurotomy using radiofrequency current, in the management of chronic low back pain: A randomized double-blind trial. Spine 2008; 33:1291-1297.

11. Cohen SP, Williams KA, Kurihara C, et al. Multicenter, randomized, comparative cost-effectiveness study comparing 0 , 1 , and 2 diagnostic medial branch (facet joint nerve) block treatment paradigms before lumbar facet radiofrequency denervation. Anesthesiology 2010; 113:395-405.

12. Endreas S, Shufelt A, Bogduk N. The risks of continuing or discontinuing anticoagulants for patients undergoing common interventional pain procedures. Pain Med 2017; 18:403-409.

13. Narouze S, Benzon HT, Provenzano $D$, et al. Interventional spine and pain procedures in patients on antiplatelet and anticoagulation medication (second edition): Guidelines from the American Society of Regional Anesthesia and Pain Medicine, the European Society of Regional Anaesthesia and Pain Therapy, the American Academy of Pain Medicine, the International Neuromodulation Society, the North American Neuromodulation Society, and the World Institute of Pain. Reg Anesth Pain Med 2018; 43:225-262.

14. Bogduk N. Anticoagulants. In: Bogduk N (ed). Practice Guidelines for Spinal Diagnostic and Treatment Procedures. 2nd ed. San Francisco, International Spinal Intervention Society, 2013: pp. 9-17.

15. Kennedy DJ, Plastaras C, Casey E, et al. Comparative effectiveness of lumbar transforaminal epidural steroid injections with particulate versus nonparticulate corticosteroids for lumbar radicular pain due to intervertebral disc herniation: A prospective, randomized, double-blind trial. Pain Med 2014; 15:548-555.

16. El-Yahchouchi C, Geske JR, Carter $R E$, et al. The noninferiority of the nonparticulate steroid dexamethasone vs the particulate steroids betamethasone and triamcinolone in lumbar transforaminal epidural steroid injections. Pain Med 2013; 14:1650-1657.

17. Gharibo C, Fakhry M, Diwan S, Kaye AD. Conus medullaris infarction after a right $L_{4}$ transforaminal epidural steroid injection using dexamethasone. Pain Physician 2016; 19:E1211-E1214.

18. Gupta S, Sharma M. Survey of awareness of the guidelines published by the Faculty of Pain Medicine and the British Pain Society. Br J Pain 2019; 13:5-6. https://journals.sagepub.com/ doi/pdf/10.1177/2049463719865408. Date accessed 05/03/2019.

19. Lau R, Stevenson F, Ong BN, et al. Achieving change in primary carecauses of the evidence to practice gap: Systematic reviews of reviews. Implement Sci 2016; 11:40.

20. Gupta S, Brown M. A guide to development, dissemination and review of guidance documents. transmitter, published by the faculty of Pain Medicine of the Royal College of Anaesthetist, London (Accepted for Publication - In Press). 